\title{
Seasonal heat content changes in the western Mediterranean Sea as a means for evaluating surface heat flux formulations
}

\author{
Gerd Krahmann, ${ }^{1}$ Friedrich Schott, and Uwe Send \\ Institut fur Meereskunde, Kiel, Germany
}

\begin{abstract}
The semienclosed western Mediterranean Sea has proven to be a useful location to evaluate surface heat flux estimates. In the past the directly measured average oceanic heat transport from the Atlantic into the Mediterranean Sea through the Strait of Gibraltar of $\sim 5.2 \pm 1.3 \mathrm{~W} \mathrm{~m}^{-2}$ has been compared to estimates of the average heat flux across the surface of the Mediterranean Sea. On long timescales both should closely balance each other. By using a monthly temperature climatology of the western Mediterranean Sea we offer the possibility to extend the comparison to the seasonal timescale. This gives additional information with which different surface heat flux data sets can be evaluated. The seasonal heat content changes of the western Mediterranean and the advective exchange of heat through the Straits of Gibraltar and Sicily are estimated on the basis of a new extensive hydrographic data set and of published values for the volume transports. To demonstrate the method, a limited number of surface heat flux data sets are compared with the oceanographically calculated counterpart. The comparison reveals that some heat fluxes do not only agree well for the long-term averages but also for the seasonal timescale, whereas others show larger deviations. The remaining rms discrepancies of $\pm 10.2 \mathrm{~W} \mathrm{~m}^{-2}$ for the best heat flux data set are smaller than the uncertainty of the oceanographic estimate and of a reasonable magnitude compared to the uncertainty of the long-term average of $\sim 5 \mathrm{~W} \mathrm{~m}^{-2}$.
\end{abstract}

\section{Introduction}

Knowledge of the heat fluxes between ocean and atmosphere is a requirement for modeling and understanding the climate system. Ocean-only numerical models depend on surface heat fluxes as a boundary condition and coupled oceanatmosphere models need reliable formulations to calculate the fluxes from the actual model state. As long as the surface heat fluxes do not reach a sufficient accuracy we will not be able to perform realistic studies with numerical models. The necessary accuracy somewhat depends on the problems to be studied: An accurate modeling of the seasonal cycle should be possible with errors of $<10 \mathrm{~W} \mathrm{~m}^{-2}$ [Taylor, 1984; World Climate Research Program, 1996], while for small long-term trends, like that of the western Mediterranean deep water [Bethoux et al., 1998; Krahmann and Schott, 1998], which is equivalent to a surface heat flux of $0.5 \mathrm{~W} \mathrm{~m}^{-2}$, accuracies an order of magnitude better are necessary.

The heat flux across the boundary between ocean and atmosphere consists of four components: shortwave and longwave radiation and latent and sensible exchange of heat. Since direct measurements are not operationally possible, estimates based on more easily accessible meteorological and oceanographical data are generally used. Relying on empirical parametrizations (commonly known as bulk formulae) which are derived from specific data sets [e.g., Dobson and Smith, 1988] these estimates may not be appropriate in all cases. One consequence of the resulting uncertainty is the existence of a number of different

\footnotetext{
${ }^{1}$ Now at Lamont-Doherty Earth Observatory, Palisades, New York. Copyright 2000 by the American Geophysical Union.

Paper number 2000JC900039.

0148-0227/00/2000JC900039\$09.00
}

empirical formulations [see, e.g., Angelucci et al., 1998; Schiano et al., 1993], each of which is adequate for the underlying database but not necessarily for all other cases.

Different parametrizations can be evaluated by comparing fluxes calculated by bulk formulae with direct flux observations or with surface heat fluxes implied by other data. A prominent example for the second method is the Mediterranean Sea. Here the long-term average surface heat fluxes can be easily compared to estimates based on the heat transport through the Strait of Gibraltar. This possibility has been used in a number of studies [Bunker et al., 1982; Garrett et al., 1993; Schiano et al., 1993; Gilman and Garrett, 1994]. The advantage of the Mediterranean Sea for such studies arises from its semienclosed nature. Exchange with other ocean basins is confined to the narrow Strait of Gibraltar and the connection with the Black Sea. Measurements indicate no relevant long-term change of the temperatures within the Mediterranean Sea. The heat transport through the straits thus must, at long timescales, be balanced by corresponding surface heat fluxes. The most recent estimate of the average heat transport through the Strait of Gibraltar of $5.2 \pm 1.3 \mathrm{~W} \mathrm{~m}^{-2}$ into the Mediterranean Sea was deduced by Macdonald et al. [1995] from moored measurements of currents and temperatures (see Table 1 for other values). The uncertainty of this oceanographic estimate of the heat transport of $<2 \mathrm{~W} \mathrm{~m}^{-2}$ is small compared to the typical uncertainties and errors of the meteorological estimates of $30-40 \mathrm{~W} \mathrm{~m}^{-2}$ [Bunker et al., 1982; Garrett et al., 1993]. Thus we can use it as a reference for the evaluation of meteorological estimates.

Bunker et al. [1982] and, later, Garrett et al. [1993] found discrepancies between commonly used bulk formula parametrizations and the Gibraltar reference value of $>30 \mathrm{~W} \mathrm{~m}^{-2}$. They explained this with shortcomings of either the meteoro- 
Table 1. Estimates of the Long-Term Average Heat Transport Through the Strait of Gibraltar

\begin{tabular}{lc}
\hline \multicolumn{1}{c}{ Reference } & Average Heat Transport, $\mathrm{W} \mathrm{m}^{-2}$ \\
\hline Bethoux $[1979]$ & -8.5 \\
Bunker et al. $[1982]$ & -5 \\
Garrett et al. $[1993]$ & -7 \\
Macdonald et al. $[1995]$ & $-5.2 \pm 1.3$ \\
\hline
\end{tabular}

The values are given as an average surface heat flux. Negative values (i.e., a heat flux from the ocean to the atmosphere) denote net heat transports from the Atlantic into the Mediterranean Sea. The first three values are simply calculated from estimates of the volume transport and the temperatures of the inflow and outflow, while the fourth value is derived from moored measurements of currents and temperatures.

logical data or the adopted parametrizations. In order to adjust the heat fluxes to match the reference, Garrett et al. [1993] proposed two different ways to correct for the discrepancies: by increasing the heat loss by evaporation or by decreasing the insolation. The two options have a different seasonal signature, but a lack of information on the seasonal variation of the Mediterranean heat content prevented these earlier investigators from evaluating the two approaches.

In two subsequent studies two different paths have been followed to reduce the discrepancies of the long-term average. Gilman and Garrett [1994] used basically the same set of parametrizations as Garrett et al. [1993] but found an error in the parametrization of the insolation and introduced the effect of aerosols into insolation. Castellari et al. [1998] and Angelucci et al. [1998] followed a second route in comparing various sets of parametrizations for the four heat flux components to examine for which set the overall agreement is best. This second approach was also followed by Schiano et al. [1993] for the comparison of in situ measurements of the longwave and shortwave components with different bulk formulae. They found a general agreement for the shortwave radiation but an underestimation of the longwave fluxes by all analyzed formulae. Big. nami et al. [1995] developed a new formulation for the longwave radiation correcting this underestimation. This new formulation was applied by Gilman and Garrett [1994] and gave good results for the Mediterranean heat budget. These results highlight the need to better understand the surface heat fluxes and their possible dependence on other local atmospheric parameters like humidity or cloud cover and type.

On the basis of a monthly temperature of the western Mediterranean Sea we develop an additional means for evaluating surface heat flux data sets. We therefore quantify the seasonal variation of the western Mediterranean heat content and the heat transport divergence through the straits of Gibraltar and Sicily. Together with the previously employed long-term average heat and freshwater fluxes through the Straits of Gibraltar this offers a third means for evaluations. To demonstrate the possibilities of our method, we perform an exemplary study of some previously published and evaluated surface heat flux data sets.

We compare our oceanic estimate with surface heat fluxes based on the monthly averages of meteorological observations of Comprehensive Ocean-Atmosphere Data Set (COADS), with two climatologies of surface heat fluxes by May [1982] and da Silva et al. [1994], and with data of the operational analysis of the European Centre for Medium-Range Weather Forecasts (ECMWF). For the computation of the surface heat fluxes from the COADS observations we chose the sets of parametrizations already applied by Garrett et al. [1993] and later modified by Gilman and Garrett [1994].

Two of the data sets (May [1982] and ECMWF) investigated in this study have been used in numerical studies of the Mediterranean Sea [Zavatarelli and Mellor, 1995; Herbaut et al., 1996]. The difficulties that numerical models of the Mediterranean Sea have up to now in correctly reproducing the formation of deep and intermediate water masses [Zavatarelli and Mellor, 1995; Herbaut et al., 1996] might at least partially arise from erroneous surface heat fluxes. Especially the modeling of the deep water formation, an important process for the vertical circulation in the western Mediterranean Sea [Schott et al., 1994], depends on the accurate knowledge of the heat loss in winter [Mertens and Schott, 1998]. Thus the extension of the comparison to the seasonal timescale may help to identify problems caused by the use of certain heat flux fields or bulk formulae.

We first introduce the different meteorological and oceanographic data sets which we have used and thereafter describe the derivation of the oceanographic estimate. We then demonstrate the evaluation of some surface heat flux sets by calculating their deviation from the oceanographic estimate. Finally, we summarize our results.

\section{Data and Methods}

For the atmospherical/meteorological side of the comparison we use seven data sets. Five of these are derived from the COADS data set [Woodruff et al., 1987] by the usage of different bulk parametrizations, one is similarly calculated from ships observations [May, 1982], and one is the output of an operational weather forecast model.

\subsection{COADS Uncorrected}

The first data set is derived from the COADS data set which is given on a monthly and $2^{\circ} \times 2^{\circ}$ grid. We used data between 1946 and 1992 to construct average seasonal cycles of the surface heat fluxes. For this, we calculated the latent, sensible, and shortwave and longwave heat flux components according the parametrizations described by Garrett et al. [1993] from sea surface temperature, air temperature, surface air pressure, specific air humidity, cloud cover, and scalar wind speed of the COADS data set. The 47 years of data were then averaged to obtain a climatological mean seasonal cycle of the heat flux.

\subsection{COADS A}

For this heat flux data set we used the same observational data as for the previous but applied option A of Garrett et al. [1993], which consisted of a $18 \%$ decrease in insolation. The application of this option creates an agreement between the long-term average heat flux and the reference heat transport through the Strait of Gibraltar.

\subsection{COADS B}

Garrett et al. [1993] gave a second option B to create the agreement with the Gibraltar reference. In this case the latent heat fluxes were increased by $33 \%$. We use option B as third heat flux data set.

\subsection{COADS GG}

Gilman and Garrett [1994] reanalyzed the COADS data using modified bulk parametrizations. The heat fluxes calculated with their formulae form the fourth COADS-derived data set. 


\subsection{COADS DS}

da Silva et al. [1994] also used COADS data to calculate worldwide surface heat fluxes. Different from the previous four COADS-derived sets, he used single observations to calculate the fluxes and averaged these afterward to form monthly means.

\subsection{May}

The sixth atmospheric data set is the surface heat flux climatology of May [1982]. This climatology was derived from ship reports of meteorological data by the usage of bulk parametrizations, similar to the COADS cases above.

\subsection{ECMWF}

As a further data set we have included surface heat fluxes of the operational analysis of the ECMWF in Reading, England, for the years 1992-1995 into our comparison. In the ECMWF model, latent and sensible heat fluxes are calculated using bulk formulae with coefficients from Louis [1979] [see also, Gleckler and Taylor, 1993] while the shortwave and longwave components are obtained from radiation models [see, e.g., Morcette, 1991]. The 6-hourly values of the four heat flux components were averaged to monthly values and integrated over the Mediterranean basins accounting for the actual area of the sea surface. The 4 years of data were then averaged to obtain an average seasonal cycle of the heat fluxes.

For the oceanographic calculations of heat content change and heat transport through the straits a new climatology of temperatures and salinities of the western Mediterranean Sea (see Krahmann [1997] and Krahmann and Schott [1998], available on the World Wide Web at http:/www.ldeo.columbia.edu/ -krahmann/thetis/thetis.html) has been used together with the latest estimates of the volume and heat transports through the Straits of Gibraltar and Sicily [Bryden et al., 1994; Macdonald et al., 1995; Astraldi et al., 1996]. The climatology was compiled from historical temperature and salinity measurements extending back to 1905 . Some 85,000 profiles were used to derive climatological values with a horizontal resolution of $1 / 2^{\circ} \times 1 / 2^{\circ}$ on 31 depth levels. The depth levels are similar to the levels of the climatology of Levitus [1982] with three additional levels in the Levantine Indermediate Water layer. A major advantage of this climatology in comparison to others [e.g., MED5 of Brasseur et al. [1996] and Brankart and Brasseur [1996]) is the inclusion of bathythermograph data collected by the French navy, which increased the number of profiles mainly in the northern western Mediterranean Sea by some 30,000. The data were binned into three-dimensional spatial and monthly temporal boxes for the period from 1905 to 1994 to calculate average values of temperature and salinity (see Figure 1 for a flowchart of the compilation). The 90 years were then averaged into one single average seasonal cycle. A subsequent application of a horizontal smoothing-interpolation routine with Gaussian weights (half width is $53 \mathrm{~km}$; cutoff radius is $106-178$ $\mathrm{km}$, depending on variable and depth) at the same time smoothed the field and filled gaps with a distance-weighted average of surrounding data points. A vertical smoothing with empirical orthogonal functions (EOF) was then applied to the resulting fields. The final field was reconstructed from only the first 10 EOFs, which explained $>99.9 \%$ of the total variance both for salinity and temperature.

We compared our climatology with the MED5 climatology of Brasseur et al. [1996] by calculating seasonal averages and found that the differences were small $\left(<0.1^{\circ} \mathrm{C}\right)$ except for the fall season. In fall, Brasseur et al. [1996] report generally higher

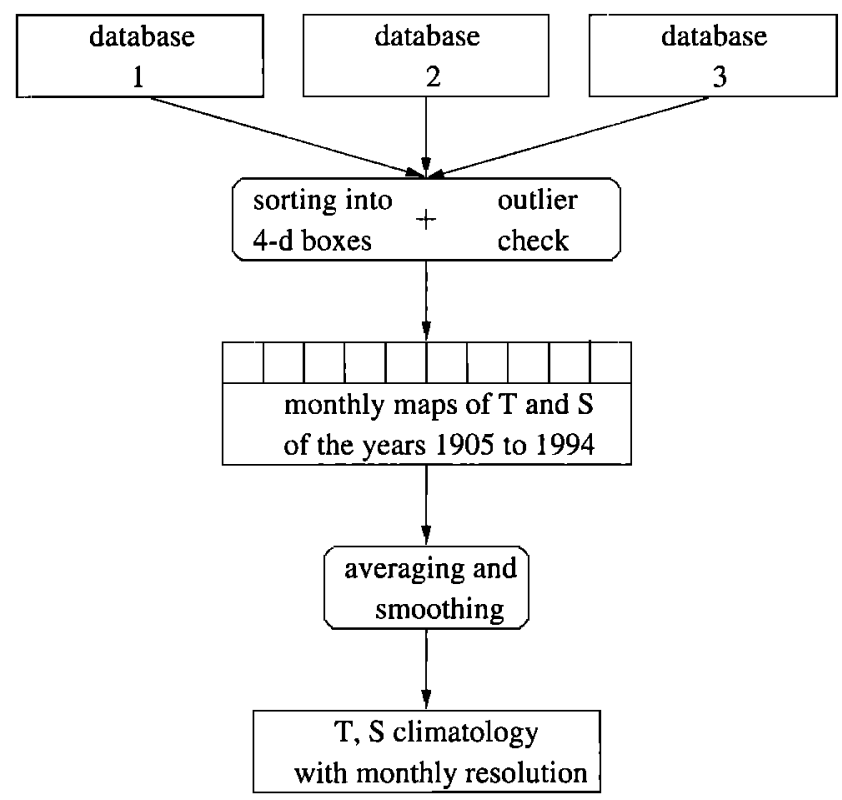

Figure 1. Flowchart describing the computational steps for the derivation of the $T-S$ climatology of the western Mediterranean Sea.

temperatures. This is related to the unequal temporal distribution of the measurements. Brasseur et al. [1996] incorporate all measurements of the fall season (October to December) without respect of the month. Since significantly more measurements were obtained in the warmer October and November than in the colder December, this leads to higher averaged temperatures. In our climatology this has been avoided by first calculating monthly averages and than averaging over the season.

\section{Seasonal Heat Budget of the Western Mediterranean}

The seasonal heat budget of the western Mediterranean Sea is composed of three components: (1) the surface heat fluxes, (2) the heat content changes of the western Mediterranean basin, and (3) the divergence of the heat transports through the Straits of Gibraltar and Sicily. Minor contributions come from the heat flux through the sea floor and the input from rivers and precipitation. With $\sim 0.15 \mathrm{~W} \mathrm{~m}^{-2}$ [Hutchinson et al., 1985] and $<1 \mathrm{~W} \mathrm{~m}^{-2}$ [Garrett et al., 1993], respectively, these are small compared to the uncertainties of the three major components. For the monthly heat budget we thus obtain

$\left(t_{\imath+1}-t_{t}\right)\left(\frac{T_{\mathrm{Gub}}-T_{\mathrm{Slc}}}{A}-F\right)-\frac{H\left(t_{\imath+1}\right)-H\left(t_{t}\right)}{A}=0$,

where $T_{\text {Gib }}$ and $T_{\text {Sic }}$ denote the monthly averaged heat transports through the Straits of Gibraltar and Sicily, respectively, $F$ is the monthly heat flux through the sea surface averaged over the same period of time and over the surface of the basin, and $H\left(t_{t+1}\right)-H\left(t_{t}\right)$ is the difference in heat content of the whole basin between the beginning $t_{t}$ and the end $t_{t+1}$ of the evaluated month. $A$ is the surface area of the western Mediterranean.

\subsection{Seasonal Heat Content Changes}

The climatological monthly heat content anomaly $H(t)$ of the western Mediterranean was calculated from the temperature and salinity data by using 


$$
H_{t}=\sum_{n=1}^{419} \sum_{m=1}^{31} c_{p}^{m n}(\theta, S) \rho^{m n} V^{m n}\left(\theta_{l}^{m n}-\theta_{\mathrm{ref}}^{m n}\right) .
$$

Here $c_{p}^{m n}(\theta, S)$ denotes the specific heat content for each climatology box, $\rho^{m n}$ is the respective density, $V^{m n}$ is the volume of the box, $\theta_{t}^{m n}$ is the average potential temperature in box $m n$ for the month $i$, and $\theta_{\text {ref }}^{m n}$ is a reference temperature. As reference we have taken the annual average temperature. The indices $n$ and $m$ loop over the horizontal and vertical grid points, respectively.

Different from other studies calculating the seasonal variation of the heat content [e.g., Moisan and Niiler, 1998], our temperature climatology allows a calculation of the heat content down to the bottom of the Mediterranean, thus avoiding uncertainties due to an unknown vertical transport of heat into a depth-limited surface layer. The seasonal cycle of the heat content changes can be derived by calculating the differences between subsequent monthly heat content anomalies giving values centered at the beginning of the months. For comparison with the average monthly heat fluxes, however, the monthly heat contents were harmonically interpolated onto the beginning of the months and the heat content changes were calculated from these values.

To estimate the uncertainty of our heat content changes, we computed a Monte Carlo test based on standard deviations of the monthly temperatures. We first calculated standard deviations of the 90 years of monthly averaged temperature data. This was independently performed for each grid point. We then derived horizontal root-mean-squares of these standard deviations to obtain one profile of uncertainties for each month of the year. For the Monte Carlo test we added independent uncertainties based on these profiles to each single grid point. One thousand realizations of heat content changes were calculated and gave monthly standard deviations of the heat fluxes between 3.6 and $4.6 \mathrm{~W} \mathrm{~m}^{-2}$. This approach covers mainly the uncertainty due to interannual variability of the temperatures. For low numbers of observations, as is frequent until the 1950s, the uncertainties from others sources, like measurement and sampling errors, are, however, indistinguishable from the interannual variability and are thus included. We thus believe that our approach covers most of the uncertainty of our calculation.

\subsection{Heat Transports Through the Straits}

The currents both in the Strait of Gibraltar and in the Strait of Sicily generally consist of eastward flow in an upper layer and westward flow in a lower layer of about equal size [Bryden et al., 1994; Astraldi et al., 1996]. Because of the upper layer being warmer than the lower, net eastward heat transports (into the basins) are achieved.

For our analysis of the seasonal surface heat fluxes we need not only the average heat transport through the straits but, more important, their seasonal variation. Since no other information is available, we have to estimate the seasonal cycles from the seasonal variation of the temperatures of the inflowing and outflowing layers together with the seasonal variation of the volume transports.

3.2.1. Long-term average. Though the long-term average heat transports through the straits of Gibraltar and Sicily are not the central point of our study we nevertheless have to establish values which we can employ in our calculations.

Early estimates of the average heat transport through the Strait of Gibraltar were based on the simple model of the average exchanging counterflows (see Table 1). For this simplified case the heat transport can be calculated from the temperature difference between inflow and outflow, the mean volume transports, the densities, and the specific heat content. Recent observations in the Strait of Gibraltar showed that the two-layer average flow model of the exchange between the basins is oversimplified [Macdonald et al., 1995]. The mean exchange flow currents are superimposed by strong highfrequency fluctuations caused by tides and atmospheric pressure differences between the Atlantic and Mediterranean areas. In the central part of the Strait of Gibraltar these temporal variations, which are mainly barotropic, exceed the average inflow and outflow velocities in amplitude and thus cause timedependent current reversals. At the same time, the depth of the interface between inflowing and outflowing watermasses is changing. The correlated variations of vertical water mass distribution and currents cause a significant contribution to the net heat transport. Macdonald et al. [1995] found from mooring data that only one third of the actual heat transport is accomplished by the mean inflows and outflows as described earlier, while two thirds arise from the correlated velocity and temperature changes. Despite the differences between these more recent observations and the earlier simple model the reported average heat transports are of similar size (see Table 1). The reason for this agreement is an overestimation of the mean volume transports in the earlier studies.

Information on the volume and heat transports through the Strait of Sicily is less well established. Observations of the volume transports and their seasonal variation cover a wide range, making it difficult to determine a reliable seasonal cycle [Astraldi et al., 1996]. Even less information exists for the average transport of heat. It is likely that a similar effect of correlated velocities and temperatures as reported for the Strait of Gibraltar is present in the Strait of Sicily, though it might be less important due to the wider geometry of the strait.

We construct here an estimate of the average heat transport through the Strait of Sicily from the heat transport through the Strait of Gibraltar and from various surface heat flux data sets. We use the spatial variation of the various surface heat flux fields to distribute the heat entering the Mediterranean Sea through the Strait of Gibraltar onto the western and eastern Mediterranean.

The heat transport through the Strait of Sicily can be derived from the surface fluxes and the heat transport through the Strait of Gibraltar via

$$
\begin{aligned}
& \overline{\Delta F}=\overline{F_{e}}-\overline{F_{w}} \\
& \overline{T_{\mathrm{Gib}}}=\overline{F_{e}} A_{e}+\overline{F_{w}} A_{w} \\
& =\overline{F_{e}} A_{e}+\left(\overline{F_{e}}+\overline{\Delta F}\right) A_{w} \\
& =\overline{T_{\mathrm{Sic}}}+\overline{T_{\mathrm{Slc}}} \frac{A_{w}}{A_{\ell}}+\overline{\Delta F} A_{w} \\
& \overline{T_{\mathrm{Sic}}}=\overline{F_{e}} A_{e} \\
& =\frac{\overline{T_{\mathrm{Glb}}}-\overline{\Delta F} A_{w}}{1+A_{w} / A_{e}},
\end{aligned}
$$

where $\overline{\Delta F}$ denotes difference between the long-term average heat fluxes of the western Mediterranean $\overline{F_{w}}$ and the eastern Mediterranean $\overline{F_{e}}, \overline{T_{\mathrm{Glb}}}$ and $\overline{T_{\mathrm{SIC}}}$ are the average heat transports through the Straits of Gibraltar and Sicily, respectively, and $A_{w}$ and $A_{e}$ are the surface areas of the western and eastern Mediterranean of $8.646 \times 10^{11} \mathrm{~m}^{2}$ and $16.703 \times 10^{11} \mathrm{~m}^{2}$, 
Table 2. Basin-Differentiated Average Surface Heat Fluxes for the Different Data Sets

\begin{tabular}{|c|c|c|c|c|}
\hline \multirow[b]{2}{*}{ Data Set } & \multicolumn{3}{|c|}{ Average Heat Flux in Mediterranean, $\mathrm{W} \mathrm{m}^{-2}$} & \multirow{2}{*}{$\begin{array}{c}\text { Difference } \\
\text { (East minus West } \\
\overline{\Delta F}, \mathrm{~W} \mathrm{~m}^{-2}\end{array}$} \\
\hline & $\underset{\bar{F}}{\text { Entire }}$ & $\frac{\text { Western }}{F_{w}}$ & $\frac{\text { Eastern }}{F_{e}}$ & \\
\hline COADS uncorrected & $+29.4 \pm 1.1$ & $+26.0 \pm 1.5$ & $+31.8 \pm 1.2$ & $+5.8 \pm 1.9$ \\
\hline COADS A & $-6.9 \pm 1.1$ & $-7.7 \pm 1.5$ & $-6.1 \pm 1.2$ & $+1.6 \pm 1.9$ \\
\hline COADS B & $-6.4 \pm 1.4$ & $-6.8 \pm 2.0$ & $-5.8 \pm 1.5$ & $+1.0 \pm 2.5$ \\
\hline COADS GG & $+0.3 \pm 1.1$ & $-2.4 \pm 1.5$ & $+2.3 \pm 1.1$ & $+4.7 \pm 1.9$ \\
\hline COADS DS & +8.7 & +6.5 & +10.2 & +3.7 \\
\hline May [1982] & +2.2 & -1.9 & +4.3 & +6.2 \\
\hline ECMWF 1992-1995 & $-3.7 \pm 4.9$ & $+4.3 \pm 6.4$ & $-8.3 \pm 4.8$ & $-12.6 \pm 8.0$ \\
\hline $\begin{array}{l}\text { Average difference } \\
\text { (excluding ECMWF) }\end{array}$ & & & & $+3.8 \pm 2.2$ \\
\hline
\end{tabular}

Heat gains are indicated by positive values. An average difference between eastern and western Mediterranean heat fluxes is estimated from the different data sets to derive the respective heat transport through the Strait of Sicily. The ECMWF values differ significantly from the others. The explanation for this difference is probably the short period covered the data and its coincidence with a phase of high values of the North Atlantic Oscillation Index [Hurrell, 1995].

respectively. For $\overline{T_{\mathrm{Glb}}}$ we use the estimate of Macdonald et al. [1995], and from Table 2 we get an estimate of the difference between heat fluxes in the eastern and western Mediterranean $\overline{\Delta F}$ of $3.8 \pm 2.2 \mathrm{~W} \mathrm{~m}^{-2}$. This number is supported by results from a numerical integration of the Mediterranean Sea with restoring boundary conditions by $W u$ and Haines [1998] who find a difference of $3.1 \mathrm{~W} \mathrm{~m}^{-2}$ between eastern and western Mediterranean heat fluxes. Inserted into (5), the values for $\overline{T_{\mathrm{Gib}}}$ and $\overline{\Delta F}$ lead to an average heat transport through the Strait of Sicily corresponding to an average surface heat loss of the eastern Mediterranean of $-3.9 \pm 2.1 \mathrm{~W} \mathrm{~m}^{-2}$. Finally, we obtain $-7.7 \pm 3.4 \mathrm{~W} \mathrm{~m}^{-2}$ for the average surface heat loss of the western Mediterranean. For the annual averages of the heat transports through the straits of Gibraltar and Sicily we thus adopt the values of -5.2 and $-3.9 \mathrm{~W} \mathrm{~m}^{-2}$, respectively.

3.2.2. Seasonal variation. Unfortunately for our study, the time series collected by Bryden et al. [1994] and Macdonald et al. [1995] during the Gibraltar experiment were too short to establish a seasonal cycle of the heat transport, so that we have to derive our own estimate. Model-derived heat transports could provide the necessary information. However, none of the models include the mostly tidal effects of correlated velocity and temperature changes in the strait as explained above and thus miss a substantial part of the heat transport.

The estimation presented here introduces the biggest uncertainty into our analysis. We establish an estimation of the seasonal variation of the heat transports through the straits of Gibraltar and Sicily together with their possible range by using various volume transports and different corrective factors for the shortcoming of the two-layer approach. We use the range of results as the uncertainty of our estimate (see Figure 2). The application of a similar factor for the seasonal heat transport variation as for the long-term average can be justified by the temperature difference between inflow and outflow into the Mediterranean Sea varying with the season and the tidal currents being independent. The result is that the covariation of temperature and current anomalies varies similar to the temperature difference.

For the Strait of Gibraltar we assume a negligible seasonal variation (Bormans et al. [1986] report a variation of only $10 \%$ )
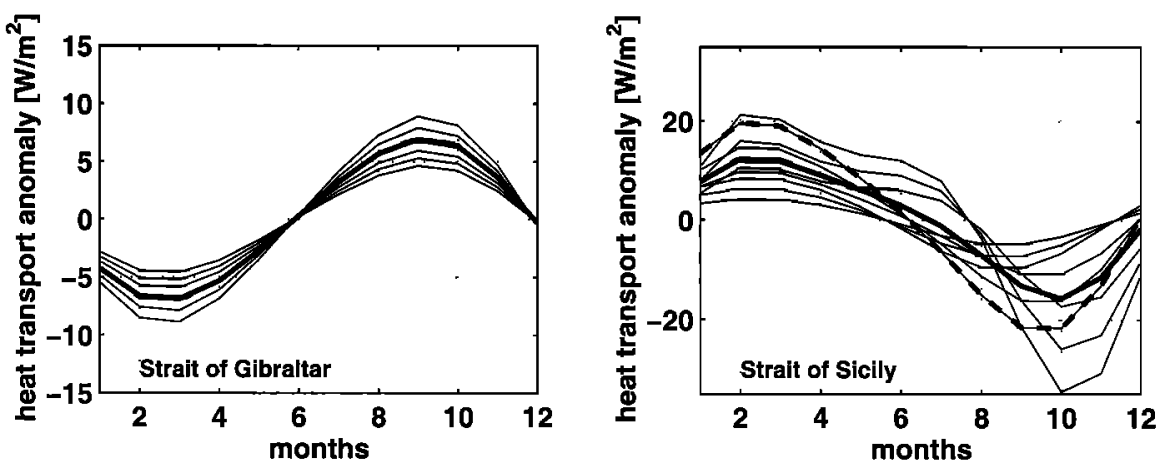

Figure 2. Range of possible seasonal variations of the heat transports through (left) the Straits of Gibraltar and (right) Sicily. The various seasonal variations were derived by multiplying climatology-derived temperatures of the inflowing and outflowing layers with different estimates of the seasonal variation of the volume transports. Additionally, we added different factors to account for the difference between the simple two-layer approach and observations [see Macdonald et al., 1995]. For the actual comparison between oceanic and atmospheric estimates of the seasonal surface heat fluxes we used the heat transports denoted with thick lines, while we took the range covered by all heat transport estimates as their uncertainty. The solid thick lines are the average of the displayed heat transports, while the dashed ones (dashed and solid line coincide in the left graph) show the configuration of volume transports and corrective factor which appears most likely to us. 


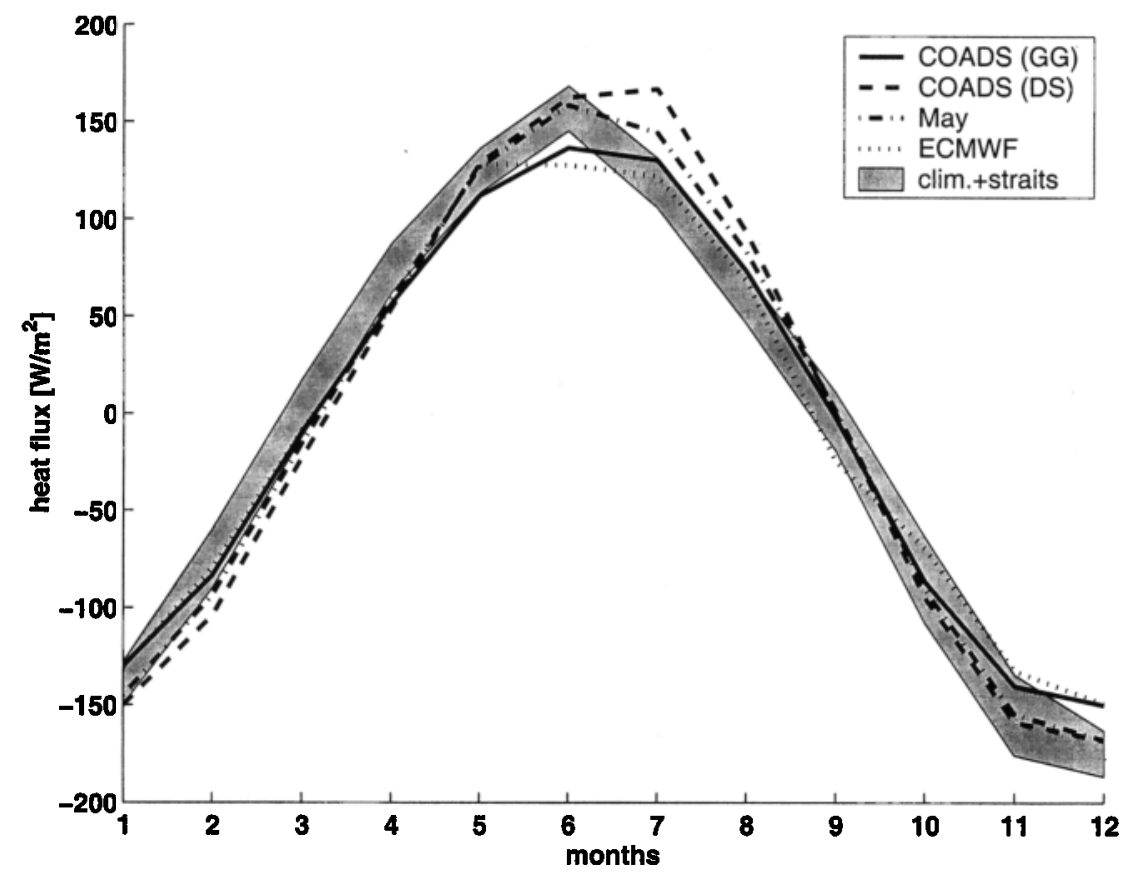

Figure 3. Seasonal cycles of surface heat fluxes for the different atmospheric data sets and the oceanographic estimate. The shaded area denotes the combined uncertainty of the estimation of the heat transport through the straits and the uncertainty of the heat content changes. The data sets have been adjusted to match the long-term average heat loss of the western Mediterranean of $-7.7 \mathrm{~W} \mathrm{~m}^{-2}$. All cycles have a comparable seasonal amplitude of about $\pm 150 \mathrm{~W} \mathrm{~m}^{-2}$. Significant differences of $50 \mathrm{~W} \mathrm{~m}^{-2}$ between the different data sets are, however, visible in summer and winter.

of the volume transports of $0.7,0.8$, and $0.9 \mathrm{~Sv}$ and vary only the temperatures of inflow and outflow. We apply corrective factors of 2 and 3 in agreement with the results of Macdonald et al. [1995].

Our estimate uses a volume transport of $0.7 \mathrm{~Sv}$ and a factor of 3. For the Strait of Sicily we use three different seasonal cycles of the volume transports together with temperatures from the climatology. To account for the possible correlations between velocities and temperatures, we apply factors from 1 to 2 , assuming that the heat transport enhancing effect is weaker in the wider Strait of Sicily than in the Strait of Gibraltar. Our estimate uses a harmonical seasonal cycle of the volume transports with a maximum of $1.45 \mathrm{~Sv}$ in winter and a minimum of $1.05 \mathrm{~Sv}$ in summer together with a factor of 2 . Two other seasonal cycles of volume transports, $0.4 / 0.6$ and $2.5 / 0.5$ $\mathrm{Sv}$ for winter/summer transports, have been included in the evaluation of the possible range. The range approximately covers observations and estimates listed by Astraldi et al. [1996], while we have chosen our estimate as the average of the listed values together with a slightly stronger winterly transport. Using these various estimates for the heat transports, we calculate the respective heat transport divergences and use the obtained range as uncertainty of our estimate.

\section{Comparison}

Mean seasonal cycles of the surface heat fluxes for the different heat flux data sets and the oceanographic counterpart are displayed in Figure 3. We have indicated the combined uncertainties of the two components of the oceanographic estimate (heat content change and heat transport through straits) by the shaded area. Seasonal amplitudes of approxi- mately $\pm 150 \mathrm{~W} \mathrm{~m}^{-2}$ are consistently present in all cycles. The seasonal heating and cooling of the surface layer can thus be modeled reasonably well with each of the data sets. There are, however, differences between the estimates of up to $50 \mathrm{~W} \mathrm{~m}^{-2}$ during summer and winter times. Especially, the winterly differences might be one of the sources for difficulties within numerical models to reproduce observed watermass formation [Herbaut et al., 1996].

To examine the differences between the atmospheric and the oceanographic estimates more closely, we subtracted the heat content changes and the heat transports from each of the atmospheric data sets. Inspection of Figures 4 and 5 gives more insight into the strengths and weaknesses of the heat flux data sets. From Figure 4 it is visible that both our estimate of the heat transports through the straits and the heat flux data sets minus the heat content change have a similar seasonal cycle with a maximum in October/November and a minimum in February/March. This agreement gives some confidence in our estimate of the heat transport divergence. At the same time, there are parts of the year when some heat flux data sets deviate significantly from the oceanographic result (July/ August and February/March). These parts distinguish the better (May and COADS GG) from the worse (COADS B and COADS uncorrected) heat flux data sets.

In Figure 5 this can be seen even better. Here only the data sets COADS GG, COADS A and May show small deviations from the zero line. The data sets COADS B, COADS uncorrected, and COADS DS reveal too large heat gains in summer. This indicates that the reduction of the insolation made by Garrett et al. [1993] and Gilman and Garrett [1994] was the correct way to close the long-term heat budget of the Mediterranean Sea. 

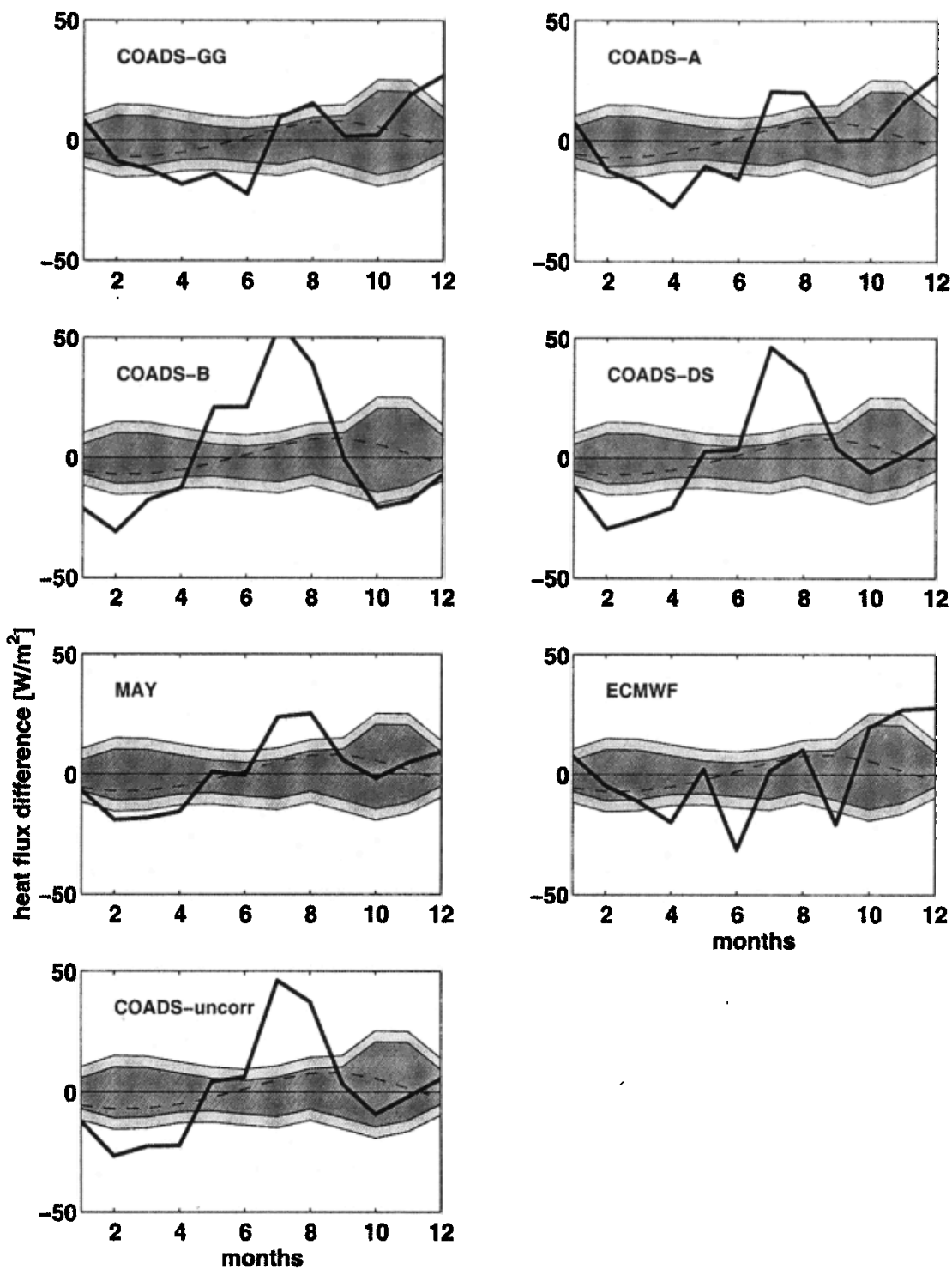

Figure 4. Seasonal cycles of the surface heat fluxes minus the heat content change of the western Mediterranean Sea (thick lines). Our estimate of the heat transport through the Straits of Gibraltar and Sicily is shown as thin solid line. The dark shaded area denotes the uncertainty of the heat transports, while the light shaded area represents the uncertainty of the seasonal heat content change of the western Mediterranean Sea.

Table 3 lists both the rms differences between the summed oceanographic estimates (heat content change and heat transport divergence) and the heat flux data sets. We have included the results for a comparison with our estimate of the heat transport divergence and with the average one as obtained from Figure 2. The results do, however, differ by $<4 \mathrm{~W} \mathrm{~m}^{-2}$. Both the differences for the unchanged heat flux data sets and the data sets adjusted to match the $-7.7 \mathrm{~W} \mathrm{~m}^{-2}$ for the long-term average heat flux of the western Mediterranean have been calculated. The values for the adjusted data sets provide a better comparison since our approach does not evaluate the long-term averages. As it can be expected from the similarity between our estimate of the heat transport divergence and the various differences between atmospheric data sets and heat content changes as apparent from Figure 5, the rms differences are all lower for the adjusted data sets. For the data sets COADS $\mathrm{A}$ and COADS $\mathrm{B}$, which were created to already match the long-term average heat flux of the Mediterranean
Sea, there is also expectedly only a small difference between adjusted and not adjusted data sets.

The smallest differences are achieved for the May [1982] and COADS GG data sets with 10.2 and $14.2 \mathrm{~W} \mathrm{~m}^{-2}$, respectively. The deviations of these two data sets are below the $15 \mathrm{~W} \mathrm{~m}^{-2}$ uncertainty of our oceanographic estimate and can thus be referred to as in agreement. Four data sets, COADS uncorrected, COADS A, COADS DS, and ECMWF, show intermediate deviations from the oceanographic estimate. Though they do not fall within the oceanographic uncertainty, they are not far off. Especially, the ECMWF cycle with its short time series might agree if a longer climatology is established. The COADS B data set, on the other hand, is too far off and should not be used.

With our study we are now able to answer the question of Garrett et al. [1993] which of their two options A and B for the modification of the bulk formulations is more realistic. The seasonal heat fluxes after option B (33\% increase in latent heat 

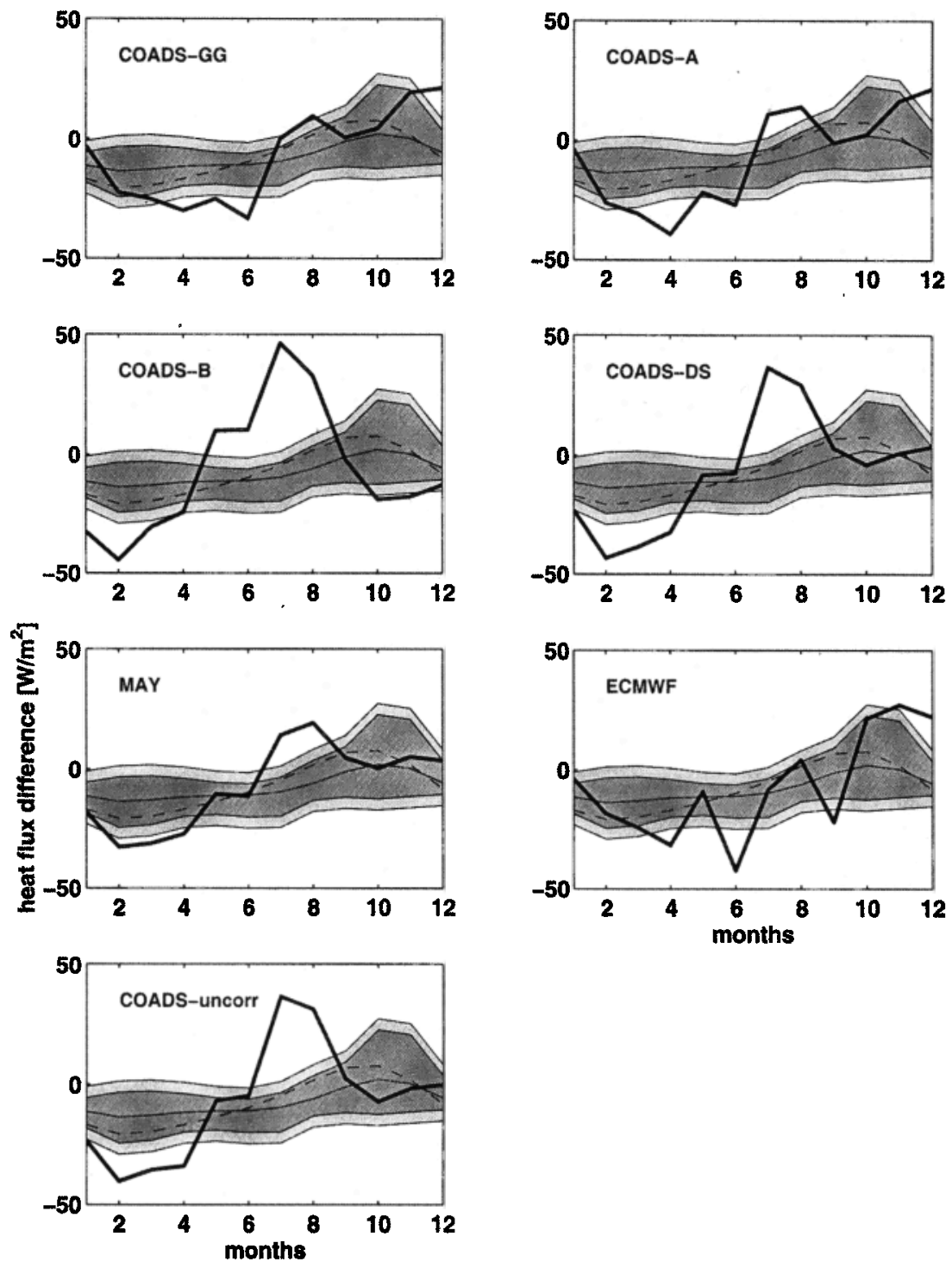

Figure 5. Same as Figure 4 but with subtracted estimate of the heat transport through the straits. Our oceanic estimate, consisting of heat content change and heat transport through the straits, is thus the zero line. The shaded area is again the range of uncertainty of our calculation.

fluxes) lead to a rms deviation of $23.6 \mathrm{~W} \mathrm{~m}^{-2}$, while we obtain a rms deviation of only $15.2 \mathrm{~W} \mathrm{~m}^{-2}$ for option $\mathrm{A}$ (18\% decrease in insolation). On the basis of the idea that commercial ships try to avoid areas with severe weather conditions which are generally colocated with areas of strong oceanic heat losses, the approach of option B had earlier been suggested by Bunker et al. [1982] to overcome the heat budget discrepancy discovered by him after the usage of common bulk parametrizations. This assumption is not supported by our results. The study of Gilman and Garrett [1994] had already pointed in this direction with the introduction the irradiation-reducing effect of aerosols, being able to reduce the discrepancy between long-term average heat fluxes and the heat transport through Gibraltar.

\section{Summary}

We have developed an additional means to evaluate surface heat flux data sets. We have therefore analyzed the heat budget of the semienclosed western Mediterranean Sea on the seasonal timescale. This complements previous studies using the
Mediterranean Sea to assess the long-term accuracy of surface heat fluxes. The new monthly climatology of Krahmann [1997] of the western Mediterranean allowed us to calculate its monthly heat content changes with sufficient accuracy. Using published values for the volume transports through the Straits of Gibraltar and Sicily, we were able to derive an estimate for the monthly surface heat fluxes which is independent from bulk formulae and atmospheric observations. The uncertainties of our oceanographic estimate are about $\pm 15 \mathrm{~W} \mathrm{~m}^{-2}$, mainly due to the unknown seasonal variation of the heat transports through the Straits of Gibraltar and Sicily, which limits our evaluation. This latter part of the uncertainty is likely to decrease should new estimates of the heat transport through the straits become available. Using our oceanic estimate, we demonstrated the evaluation on seven previously published surface heat flux data sets: five COADS-derived data sets, the surface heat fluxes after May [1982], and a 4-year average of ECMWF operational analysis heat fluxes.

A seasonal cycle of about $\pm 150 \mathrm{~W} \mathrm{~m}^{-2}$ was present in all 
Table 3. RMS Deviations Between the Combined Oceanographic Estimates (Heat Content Change and Heat Transport Divergence) and the Different Atmospheric Estimates of the Monthly Surface Heat Fluxes

\begin{tabular}{lccccc}
\hline & \multicolumn{2}{c}{$\begin{array}{c}\text { Our Heat } \\
\text { Transport, W m }\end{array}$} & & \multicolumn{2}{c}{$\begin{array}{c}\text { Average Heat } \\
\text { Transport, W m }\end{array}$} \\
\cline { 2 - 3 } \cline { 5 - 6 } \multicolumn{1}{c}{ Data Set } & Adjusted & $\begin{array}{c}\text { Not } \\
\text { Adjusted }\end{array}$ & & Adjusted & $\begin{array}{c}\text { Not } \\
\text { Adjusted }\end{array}$ \\
\cline { 2 - 3 } COADS uncorrected & 18.0 & 38.8 & & 21.5 & 40.5 \\
COADS A & 15.2 & 15.2 & & 17.0 & 17.0 \\
COADS B & 23.6 & 23.6 & & 26.2 & 26.2 \\
COADS GG & 14.2 & 15.3 & & 15.2 & 16.3 \\
COADS DS & 18.1 & 23.4 & & 21.7 & 26.3 \\
May [1982] & 10.2 & 12.4 & & 13.9 & 15.6 \\
ECMWF & 18.5 & 24.3 & & 18.2 & 24.1 \\
\hline
\end{tabular}

The different heat fluxes are composed of the seven introduced data sets both with and without adjustment to the average heat flux of the western Mediterranean of $-7.7 \mathrm{~W} \mathrm{~m}^{-2}$. Our heat transport denotes that we have used the heat transport divergence which seemed to us the most likely, while average heat transport denotes that the average of all heat transports in Figure 2 has been used.

evaluated data sets as well as in the oceanographic estimate. The analysis of the differences between the oceanographic and the atmospheric seasonal heat flux estimates revealed rms deviations between 10 and $25 \mathrm{~W} \mathrm{~m}^{-2}$. The better of the heat flux data sets thus agree within the uncertainty of the oceanographic estimate and no further statement of the quality of these atmospheric heat flux data sets is possible from our analysis. At the high end of the deviations we can say that the atmospheric heat flux data sets are not in agreement with the oceanographic data. Using the uncertainty of the oceanographic data estimate of $\pm 15 \mathrm{~W} \mathrm{~m}^{-2}$ as a delimiter between agreeable and nonagreeable atmospheric heat flux estimates, we find that the seasonal variations of May [1982] and Gilman and Garrett [1994] COADS GG are good, while the others show a too high deviation. Though our study is limited by the oceanographic data, we find that the better data sets reach an accuracy which is adequate for the modeling of the seasonal temperature variation of the ocean. For small long-term changes of temperatures, however, like those of the western Mediterranean deep water, an accuracy of $<1 \mathrm{~W} \mathrm{~m}^{-2}$ would be necessary, which seems to be impossible to achieve with current bulk formulae and observational data.

This study did not evaluate all available surface heat flux data sets but simply demonstrated the method on a restricted subset. We invite interested groups to use our oceanic estimate to evaluate surface heat flux data sets or parametrizations. For the future an improved knowledge of the seasonal variation of the heat transports through the Straits of Gibraltar and Sicily could significantly improve the uncertainties of our approach.

\section{References}

Angelucci, M. G., N. Pinardi, and S. Castellari, Air-sea fluxes from operational analysis fields: Intercomparison between ecmwf and ncep analyses over the mediterranean sea, Phys. Chem. Earth, 23, 569-574, 1998.

Astraldi, M., G. P. Gasparini, S. Sparnocchia, M. Moretti, and E. Sansone, The characteristics of the water masses and the water transport in the Sicily Strait at long time scales, Bull. Inst. Oceanogr., Numero Spec., 17, 95-115, 1996.

Bethoux, J. P., Budgets of the Mediterranean Sea: Their dependence on the local climate and on the characteristics of the Atlantic waters, Oceanol. Acta, 2, 157-163, 1979.

Bethoux, J. P., B. Gentili, and D. Tailliez, Warming and freshwater budget change in the mediterranean since the $1940 \mathrm{~s}$, their possible relation to the greenhouse effect, Geophys. Res. Lett., 25, 1023-1026, 1998.

Bianami, F., S. Marullo, R. Santoleri, and M. E. Schiano, Longwave radiation budget in the Mediterranean-Sea, J. Geophys. Res., 100, 2501-2514, 1995.

Bormans, M., C. Garrett, and K. T. Thompson, Seasonal variability of the surface inflow through the strait of gibraltar, Oceanol. Acta, 9, 403-414, 1986.

Brankart, J. M., and P. Brasseur, The general circulation in the Mediterranean Sea: A climatological approach, J. Mar. Sci., 18, 41-70, 1996.

Brasseur, P., J. M. Beckers, J. M. Brankart, and R. Shoenauen, Seasonal temperature and salinity fields in the Mediterranean Sea: Climatological analyses of a historical data set, Deep Sea Res., Part II , 43, 159-192, 1996.

Bryden, H. L., J. Candela, and T. H. Kinder, Exchange through the strait of gibraltar, Prog. Oceanogr., 33, 201-248, 1994.

Bunker, A. F., H. Charnock, and R. A. Goldsmith, A note on the heat balance in the Mediterranean and Red Seas, J. Mar. Res., 40, 73-84, 1982.

Castellari, S., N. Pinardi, and K. Leaman, A model study of air-sea interactions in the Mediterranean Sea, J. Mar. Syst., 18, 89-114, 1998.

da Silva, A. M., C. C. Young, and S. Levitus, Atlas of Surface Marine Data 1994, vol. 1, Algorithms and Procedures, Tech. Rep. 6, Natl. Oceanic and Atmos. Admin., Silver Spring, Md., 1994.

Dobson, F. W., and S. D. Smith, Bulk models of solar radiation at sea, Q. J. R. Meteorol. Soc., 114, 165-182, 1988.

Garrett, C., R. Outerbridge, and K. Thompson, Interannual variability in Mediterranean heat and buoyancy fluxes, J. Clim., 6, 900-910, 1993.

Gilman, C., and C. Garrett, Heat flux parameterizations for the Mediterranean Sea: The role of atmospheric aerosols and constraints from the water budget, $J$. Geophys. Res., 99, 5119-5134, 1994.

Gleckler, P. J., and K. E. Taylor, The effect of horizontal resolution on ocean surface heat fluxes in the ECMWF model, Clim. Dyn., 9, $17-32,1993$

Hurrell, J. W., Decadal trends in the North Atlantic Oscillation: Regional temperatures and precipitation, Science, 269, 676-679, 1995.

Hutchinson, I., R. P. von Hersen, K. E. Louden, J. G. Sclater, and J. Jemsek, Heat flow in the Balearic and Tyrrhenian Basins, western Mediterranean, J. Geophys. Res., 90, 685-701, 1985.

Krahmann, G., Saisonale und zwischenjährliche Variabilität im Westlichen Mittelmeer-Analyse historischer Daten, Ph.D. thesis, Inst. fur Meereskunde, Kiel, Germany, 1997.

Krahmann, G., and F. Schott, Long-term increases in western Mediterranean salinities and temperatures: Anthropogenic and climatic sources, Geophys. Res. Lett., 25, 4209-4212, 1998.

Levitus, S., Climatological atlas of the world ocean, Tech. Rep. 13, Nav. Oceanogr. and Atmos. Res. Lab., Stennis Space Center, Miss., 1982.

Louis, J.-F., A parametric model of vertical eddy fluxes in the atmosphere, Boundary Layer Meteorol., 17, 187-202, 1979.

Macdonald, A. M., J. Candela, and H. L. Bryden, An estimate of the net heat transport through the Strait of Gibraltar, in Seasonal and Interannual Variability of the Western Mediterranean Sea, Coastal Estuarine Stud., vol. 46, edited by P. E. L. Violette, pp. 13-32, AGU, Washington, D. C., 1995.

May, P. W., Climatological flux estimates in the Mediterranean Sea; part I, Winds and wind stresses, Tech. Rep. 54, Nav. Oceanogr. and Atmos. Res. Lab., Stennis Space Center, Miss., 1982.

Mertens, C., and F. Schott, Interannual variability deep water formation in the northwestern Mediterranean, J. Phys. Oceanogr., 28, 1410-1424, 1998.

Moisan, J. R., and P. P. Niiler, The seasonal heat budget of the north pacific: Net heat flux and heat storage rates $(1950-1990), J$. Phys. Oceanogr., 28, 401-421, 1998.

Morcette, J.-J., Radiation and cloud radiative properties in the European Centre for Medium Range Weather Forecasts forecasting system, J. Geophys. Res., 96, 9121-9132, 1991.

Schiano, M. E., R. Santoleri, F. Bignami, R. M. Leonardi, S. Marullo, and E. Böhm, Air-sea interaction measurements in the west Medi- 
terranean Sea during the Tyrrhenian eddy multiplatform observations experiment, J. Geophys. Res., 98, 2461-2474, 1993.

Schott, F., M. Visbeck, and U. Send, Open ocean deep convection, Mediterranean and Greenland Seas, in Ocean Processes in Climate Dynamics: Global and Mediterranean Examples, edited by P. Malanotte-Rizzoli and A. R. Robinson, pp. 203-225, Kluwer Acad., Norwell, Mass., 1994.

Taylor, P. K., The determination of surface fluxes of heat and water by satellite microwave radiometry and in situ measurements, in LargeScale Oceanographic Experments and Satellites, edited by C. Gautier and M. Fieux, pp. 223-246, D. Reidel, Norwell, Mass., 1984.

Woodruff, S. D., R. J. Sleutz, R. L. Jenne, and P. M. Steurer, A comprehensive ocean-atmosphere data set, Bull. Am. Meteorol. Soc., $68,1239-1250,1987$.

World Climate Research Program, Scientific plan for the world ocean experiment wcrp-6. 83 pp., Geneva, 1996.
$\mathrm{Wu}, \mathrm{P}$., and $\mathrm{K}$. Haines, The general circulation of the Mediterranean Sea from a 100-year simulation, J. Geophys. Res., 103, 1121-1135, 1998.

Zavatarelli, M., and G. L. Mellor, A numerical study of the Mediterranean Sea circulation, J. Phys. Oceanogr., 25, 1384-1414, 1995.

G. Krahmann, Lamont-Doherty Earth Observatory of Columbia University, Oceanography 206-C, RT 9W, Palisades, NY 10964-8000. (krahmann@ldeo.columbia.edu)

F. Schott and U. Send, Institut für Meereskunde, Dusternbrooker Weg 20, 24105 Kiel, Germany. (fschott@ifm.uni-kiel.de)

(Received February 17, 1999; revised January 25, 2000; accepted January 28, 2000.) 